\title{
Culture as a Determinant in Students' Acceptance of Gamified Learning
}

\author{
Filomachi Spathopoulou \\ Liberal Arts, American University of the Middle East, Egaila, Kuwait
}

\section{Email address:}

Filomachi.spathopoulou@aum.edu.kw

\section{To cite this article:}

Filomachi Spathopoulou. Culture as a Determinant in Students' Acceptance of Gamified Learning. International Journal of Education, Culture and Society. Vol. 4, No. 5, 2019, pp. 76-80. doi: 10.11648/j.ijecs.20190405.11

Received: July 18, 2019; Accepted: September 10, 2019; Published: September 24, 2019

\begin{abstract}
Nowadays, higher learning institutions in various countries across the globe are incorporating gamification in their respective curriculum in an attempt to create learning experiences that can motivate as well as actively engage learners in learning activities that they would otherwise find boring. While incorporating gamification in higher education curriculum, it is crucial to address the differences in students' behavior or perception due to their cultural differences. Gamification stands out as one of the effective e-learning approaches in motivating learners to actively participate in learning activities that they find uninteresting. To successfully incorporate gamification in various lectures, it is imperative for instructors and policy makers to comprehensively understand the involved students' cultures. This is because the knowledge of the impact of culture in higher learning plays a crucial role in enabling policy makers in the education sector to develop viable approaches of incorporating gamification in the students' learning process. Gamification is a vital tool in facilitating students' learning process as well as the creation of viable teaching models in higher learning institutions. However, there should be a remarkable balance between the application of gamification and time management in order to ensure effective delivery of instruction to students. At the same time, a culture of dedication and focus on personal growth in relation to gamification and learning should be promoted in order to ensure students are always motivated to pursue their studies. This paper aims at providing a critical examination of the effect of culture in relation to gamification in higher learning education.
\end{abstract}

Keywords: Gamified Learning, Gamified Lectures, Culture, Higher Education, Motivation

\section{Introduction}

Culture dictates most of the societal views and societal aspects such as norms, customs, language, values, mores, and rules. This implies that culture is a vital segment in the education sector. The seven core factors, which shape culture, include customs and traditions, social formulations, language, religion, economic structure, and forms of governance. In the current technological era, culture significantly influences students' learning process in various higher learning institutions [1]. Digital technology is a decisive factor that distinguishes today's students from those of previous years although it is safe to say that current generations also differ in the way they perceive the world around them, the way they socialize and the way they learn. Technology has, however, changed not only the learning dynamics but also the way students access information [2]. To integrate technology into teaching and learning (e- learning, m-learning, gamified learning etc.) it is important to ensure that its use will meet with the acceptance and approval of all those involved in the process.

According to AlOteawi an important factor that can determine the level of one's acceptance of technology is culture [3]. It is therefore necessary to start by trying to understand the cultural particularities of the target population in order to use this understanding as a foundation for the integration of technology-based teaching [4]. Research has shown that students' cultural norms become very important when it comes to introducing technology-based teaching, and special consideration should be given to students' perceptions when planning and devising material [5]. According to Kim, Song, Lockee and Burton some cultural practices tend to motivate students in higher learning by supporting the application of technology in the education system such as a gamification whereas others derail the learning process by failing to support crucial technologies 
that can facilitate students' learning [6]. This article aims at providing a critical examination on the effect of culture in relation to gamification in higher learning education.

\section{The Cultural Parameter of Gamification in Higher Learning Institutions}

Gamification involves the application of game elements in non-gaming contexts with the purpose of improving user engagement, motivation as well as making it easy for people to learn various concepts [1]. Nowadays, higher learning institutions in various countries across the globe are incorporating gamification in their respective curriculum in an attempt to create learning experiences that can motivate as well as actively engage learners in learning activities that otherwise they would find boring. While incorporating gamification in higher education curriculum, it is crucial to address the differences in students' behavior or perception due to their cultural differences. It is evident that different cultures have different beliefs. Consequently, elements of the gamified course content should be localized to synchronize with the perceptions or beliefs associated with the culture of the targeted group of students. If the beliefs and cultural practices of the target audience are not put into consideration, the concept of gamification cannot have a significant effect in improving the learning experiences of students in the targeted higher learning institutions [7].

Gamification of the educational system in higher education filters gendered ideologies in various ways with some gaming experts designing the gamified lessons based on what pleases them or what the involved lecturers have recommended. This implies that any form of masculinity and femininity exaggeration can distort students' values, their perception of reality, acceptance and motivation. Masculinity and femininity refer to the degree in which a person sees $\mathrm{him} /$ herself as masculine or feminine depending on what it means to be a man or a woman in a given culture. According to Matsumoto and Juang, masculinity in a society depicts desire for achievement, heroism, self-confidence and material reward for success while femininity depicts a liking for cooperation, care and quality of life [8]. In the American culture, women tend to be more sexualized, and the society tends to accept this practice. It is a way of life for the American society hence gamified lectures that over sexualize women tend to motivate students more since their attention is drawn to it.

This is not the case for Arab countries where the practice of sexualizing women is considered a taboo. Consequently, any gamified lecture that represents women as a sex symbol can demoralize Arab students since their culture requires women to dress decently as a show of obedience to the Muslim religion. If a gamified course content presents women without a head covering, students can consider it as a violation of their cultural beliefs because in the Arabic countries, the head covering is regarded as a symbol of womanhood. Moreover, in Arabic culture, men are expected to behave in an authoritative way and they are considered influential figures in the society. Based on this perspective, any gamified content that does not present men in a patriarchal manner may not bode well with female students who do not expect to be seen at the same level as their male counterparts. They may feel highly demotivated and their academic performance may start to deteriorate [9].

\subsection{The Problem with Metaphors, Words and Symbols}

Gamified lectures are more than just the visuals. Representational variations also exist in terms of metaphors, words and symbols. They are applicable to cross-cultural analogies where they are used to induce emotion to students. In these lectures, metaphors can help describe people, processes, values and objects. In different cultural settings, metaphors are interpreted differently. For example, the symbol for "thumb up" could be perceived as something positive in one culture or as an insult in another culture [10]. This calls for careful consideration if metaphors are going to be used in preparation of gamified lectures for students. It is important for lecturers to ensure that all the metaphors included in a gamified course convey the intended information based on the culture associated with the students in the targeted higher learning institutions. Any metaphors that possess a negative meaning to a certain culture do not draw any motivation from the students during the learning process because they would feel that the professor did not consider them during the preparation process [9]. For instance, unlike in the West, metaphors in the Arabic countries are confined in the traditional poetry. It is also worth noting that some of the linguistic expressions adopted in English pose challenges in the comprehension of the course content for Arab students. Thus, for gamification to work effectively in higher learning institutions across the Arabic World, it is advisable for lecturers to use metaphors and linguistic expressions that do not pose a communication barrier for the target audience.

\subsection{The Issue with Colors}

While incorporating gamification in various lectures, it is advisable for the involved instructors to ensure that colors used conform to the colors associated with the respective students' cultural backgrounds. McAuliffe contends that if color is culturally situated, it possesses a meaning and signs [11]. For instance, in America, red color is associated with danger while the Chinese link it with happiness. White color is associated with purity in America while the Chinese and Japanese people relate it to death. Moreover, Arabic cultures relate green color with generosity, strength and fertility while the French relate it to criminality. This implies that manipulation of color in gamification has a significant impact on students' perceptions and attitudes. It influences the students' acceptance and recognition of the gamified lectures hence affecting their motivation. For Arabic cultures, white, green and blue are mostly used in gaming systems since they 
represent purity, generosity and protection respectively [11]. For the gamified courses, these colors would prove successful in engaging the students and increasing their willingness as well as motivation to learn.

\subsection{The 'Uncertainty Avoidance' Parameter}

Another cultural aspect that can affect motivation in gamified learning is uncertainty avoidance. This refers to the difference on the amount of tolerance for uncertainty and ambiguity in a society. There are cultures that strictly follow traditions, a way of doing things, laws, and absolute truth. They are said to have high uncertainty avoidance because they do not readily accept changes as compared to the cultures with low uncertainty avoidance. Gamified lectures in higher education should put this into consideration. For example, Arab students have a low tolerance to gamified lectures that go against their Islamic teaching and traditions as they are afraid of the effect they might have on their local culture and identity [12]. They would rather stop an engagement than sit all the way through it. Less satisfaction causes the students to lose their motivation to learn. However, cultures with low avoidance tolerance can easily embrace any changes brought about by the gamified lectures without any hesitation. Students from such cultures become highly motivated and eager to learn new things, thus improving their academic performance.

\subsection{Stereotypes}

According to Cole, it has become a norm that most villains are associated with non-Western communities. This has been evident throughout media history. The villains are always depicted as enemies and hostile beings. At the end, they are always defeated showing their weakness, lack of effort or strategy. It causes an exaggeration of cultural differences and a presumption of Western superiority. This is referred to as orientalism. This kind of portrayal is not pleasing to the Arab culture and can cause lack of motivation to students as they ask themselves "why are we always the bad guys?" [13]. It is critical for instructors to put this into consideration when preparing gamified lectures. They have to make it more appealing to the students for maximum engagement. Otherwise, the Arab students will feel alienated and lose motivation in their studies. Going against this tendency in gamification can bring about a positive effect. Giving both cultures, same chances and the same opportunities or portraying them to be equals in a lecture can make the students to be actively involved in it. Maximum engagement is an indication that all the students are motivated and the lecture or course will be a success.

\subsection{The Religious Factor}

In the Arabic culture, religion influences how people relate with each other and the way students are taught in various higher learning institutions. Each member of society has a clear role to play. The elders have the authority to communicate with young people including the higher education learners in the community. Most of the religious people in Arabic culture tend to be conservative and encourage the aspect of achieving the goal of spiritual life. There is hence limited adoption of new practices such as gamification in the course of learning [14]. Moreover, the interaction of people at family level is highly depended on the nature of religion and the culture of respect. Mazur argues that the levels of gender relations, as well as social classes, are regulated by culture of the religion of a given community. Students from households that embrace open policies and adoption of new practices tend to be more willing and motivated to engage in gamified learning [15].

\subsection{The Culture of Peer Coaching}

A study conducted on the learning process of Arab students by Alothman, Robertson \& Michaelson indicates that the culture of peer coaching plays a crucial role in encouraging sharing of skills among students. The level of peer counseling culture hence influences integration of gamification in higher learning [16]. Weinberg claims that in the Arabic culture, the main activities include sharing of advice and being clear and open to the other party [17]. The outcome is hence the creation of trust and teamwork something which leads to motivation in the course of the higher learning process. A peer coaching culture is hence crucial since it gives one an exposure to professional activities and tasks in the course of learning [18]. There is also a sharing of the advice on how to improve on working on class assignment as well as teamwork and goals of engaging others.

\subsection{Cultural Intelligence, Time Management and the Role of Societal Culture}

Farber contends that the role of cultural intelligence and time management skills are a vital aspect in the course of application of gamification in higher learning. One of the developments of time management skills, specifically the cognitive dimension skills, is natured by the cultural values. Students who have gained strong cultural understanding or the rational component of cultural intelligence tend to embrace gamification sportively. During higher learning, students have the ability to develop and acquire social skills, which allow them to understand others in a better way [19]. At the same time, they have the ability to make judgments based on conceptual frameworks and better use of language in the course of learning. Moreover, students who are creative and innovative tend to find gamification as a tool of motivation in learning compared to those who do not embrace the practice [18]. Notably, students in higher learning who are accommodative tend to improve on social networking skills in the course of gamification and hence motivation in learning. The approach leads to less friction and social challenges, hence the growth of unity and cooperation among student teams in the course of the learning process.

According to Weinberg, cultural understanding is a crucial 
aspect since it models students in relation to education and gamification [17]. Values in the Arabic culture are based on practices such as effective time management, and focus on growth helps in handling education and learning activities [6]. Notably, the Arabian culture of tolerance plays an integral role in ensuring that people exercise the right etiquette, acknowledge each other's strengths, and treat each other with respect. This, in turn, ensures that students adopt the right behaviors and approaches while engaging in gamification learning. Since the students have serious roles to play when making long-term plans, it is crucial to embrace the right aspect of culture and inclusion of the other people [20].

During school time, students are able to improve on management as well as organizational change and development, something that leads to better mastery of the role of gamification in the course of learning. Some of the things Arabic culture instills to the students include delegation and deliberate practice in the course of life duties. Delegation is one of the ways which ensures that there is smooth working through sharing of the duties in higher education. In a case whereby one is given duties to undertake, there is mastery of the working conditions as well as learning new skills. Peer coaching culture also helps one to go through the process of change effectively. It is a good exposure since one works with the peer coach closely and consequently there is improvement of the learning skills [14]. It is hence evident that Arabic culture of peer counseling and coaching practices leads to the acquisition of gamification skills and hence motivation in the course of learning.

Close examination of the Arab students shows that they tend to portray their societal culture in the course of learning. Alothman, Robertson and Michaelson argue that Arab students have been found to possess strong values, which bind people together. The most important values and beliefs in the community include the culture of cooperation, group harmony, modesty, and patience. There is a practice of cooperation in the groups from tribal to family lines. People from Asian regions believe in working together with a view of promoting unity and strong ties in their families [16]. Additionally, competition is not very high, since groups do not outdo each other in most cases. The spirit of cooperation has led to the growth of family businesses in the country. The Arabic culture creates a sense of trust and hence pulling of resources in a common pool for education and investment purposes [21]. Teamwork has led to sharing of duties with the aim of impacting the less fortunate in the country. The community hence has strong ties on working together. The effect of gamification is therefore vital in the course of student motivation. Gamification tends to give students a chance to work as a team, enhancing their performance.

\section{Conclusion}

Gamification stands out as one of the effective elearning approaches in motivating learners to actively participate in learning activities that they find uninteresting. To successfully incorporate gamification in various lectures, it is imperative for instructors and policy makers to comprehensively understand the involved students' cultures. This is because the knowledge of the impact of culture in higher learning plays a crucial role in enabling policy makers in the education sector to develop viable approaches of incorporating gamification in the students' learning process. Gamification is a vital tool in facilitating students' learning process as well as the creation of viable teaching models in higher learning institutions. However, there should be a remarkable balance between the application of gamification and time management in order to ensure effective delivery of instruction to students. At the same time, a culture of dedication and focus on personal growth in relation to gamification and learning should be promoted in order to ensure students are always motivated to pursue their studies.

\section{References}

[1] Nicholson, S. (2015). A RECIPE for meaningful gamification. In T. Reiners, \& L. C. Wood (Eds.), Gamification in education and business (pp. 1-20). New York: Springer.

[2] Twenge, J. (2017). IGen: Why Today's Super-Connected Kids Are Growing Up Less Rebellious, More Tolerant, Less Happy--and Completely Unprepared for Adulthood--and What That Means for the Rest of Us (p. 24). New York, NY: ATRIA Books.

[3] Al-Oteawi, S. (2002). The perceptions of Administrators and teachers in utilizing information technology in instruction, administrative work, technology planning and staff development in Saudi Arabia (p. 248). Doctoral Dissertation, Ohio University.

[4] Hunaiyyan, A. A., Alhajri, R. A., Sharhan, S. A. (2018). Perceptions and challenges of mobile learning in Kuwait. Journal of King Saud University - Computer and Information Sciences, 30 (2), 279-289.

[5] Hamidi, H. Chavoshi, A. (2018). Analysis of the essential factors for the adoption of mobile learning in higher education: A case study of students of the University of Technology, Telematics Informatics, 35 (4), 1053-1070.

[6] Kim, S., Song, K., Lockee, B., \& Burton, J. (2018). Gamification in learning and education: Enjoy learning like gaming (pp. 25, 36). Cham: Springer.

[7] Dicheva, D., Dichev, C., Agre, G., \& Angelova, G. (2015). Gamification in education: A systematic mapping study. Educational Technology \& Society, 18 (3), 75-88.

[8] Matsumoto, D. R., \& Juang, L. P. (2017). Culture and psychology (p. 82). Boston. MA: Cengage Learning.

[9] Alomar, N., Vanissa, W., \& Gary, W. (2016). The design of a hybrid cultural model for Arabic gamified systems. Computers in Human Behavior, 472-485.

[10] Dickins, J., Hervey, S., \& Higgins, I. (2016). Thinking Arabic translation: A course in translation method: Arabic to English (p. 146). Abingdon: Routledge. 
[11] McAuliffe, M. (2016). Through the color lens (p. 59). Peregian Beach, Qld. Oxford Global Press.

[12] AlMarshedi, A., Warnick, V., Willis, G., \& Ranchhod, A. (2017). Gamification and behaviour. Gamification, 19-29.

[13] Cole, J. (2017). Trump on Islam: Neo-Orientalism and AntiShi' 'ism. The Washington Report on Middle East Affairs, 36 (4), 8 .

[14] Boud, D., \& Falchikov, N. (2016). Rethinking assessment in higher education: Learning for the longer term (pp. 87-89). Abingdon: Routledge.

[15] Mazur, B. (2015). Cultural diversity in organizational theory and practice. Journal of Intercultural Management, 2 (2), pp. $5-19$.

[16] Alothman, M., Robertson, J., \& Michaelson, G. (2017). Computer usage and attitudes among Saudi Arabian undergraduate students. Computers \& Education, 110, 127142 .
[17] Weinberg, B. (2011). Online games and social life: Managing social media games. Games and Horizons, 54 (3), 275-282.

[18] Haiken, M., \& Matera, M. (2017). Gamify literacy: Boost comprehension, collaboration, and learning (pp. 110-113). Portland, Oregon: International Society for Technology in Education.

[19] Farber, M. (2015). Gamify your classroom: A field guide to game-based learning. New York: Peter Lang.

[20] Zabadi, A. M., \& Al-Alawi, A. H. (2016). University students' attitudes towards e-learning: University of Business \& Technology (UBT)-Saudi Arabia-Jeddah: A case study. International Journal of Business and Management, 11 (6), 286-295.

[21] Yakaboski, T., Perez-Velez, K., \& Almutairi, Y. (2016). Collectivists' decision-making: Saudi Arabian graduate students' study abroad choices. Journal of International Students 2017 Vol 7 Issue 1, 7 (1), 94-112. 